\title{
Research on Lightning-shielding Design of a Transmission Line
}

\author{
Minghao Zhang \\ Branch of Electric Power Transformation, Liaoning State Grid Electric Power Transmission \& Transformation Engineering \\ Company \\ Shenyang, China \\ zhangminghao2008@126.com
}

\begin{abstract}
Development of the national economy, the demand for electricity has grown exponentially, while the power supply reliability play a key role in economic development, so the reliable operation of the grid also put forward higher requirements. Lightning trip is the biggest threat to the power grid, accounting for $\mathbf{7 0}$ to 90 percent of the power grid failure. Which is more likely to be struck by lightning overhead transmission lines, thus enhancing the lightning overhead lines and lightning short-circuit fault containment sphere of influence, a transmission line in a very important part of the design. Two ways for lightning overhead lines is proposed to reduce ground resistance overhead transmission lines and improve the level of the line itself mine-resistant design.
\end{abstract}

Keywords-transmission line; lightning-shielding; design; research

\section{INTRODUCTION}

Transmission line is the main artery of the power system, it tremendous power delivered to all sides, is to connect the various substations, all major users link. Safe operation of the transmission line, the direct impact on the stability of the grid and reliable power supply to the user. Therefore, the safe operation of the transmission line to occupy a pivotal position in the grid, with the irreplaceable position, it will power plants produce electricity delivered to the load center, connecting the various substations, all major users of the link, it's safe to run occupy a pivotal position in the grid. Therefore, we must ensure the safety of transmission of transmission lines, to provide customers with a secure and stable electricity.

A large number of transmission lines through the plains, mountains, rivers and lakes across the geographical conditions and weather conditions encountered are different, so the chance of being struck by lightning more. According to statistics, China's electric power system, all kinds of accidents, obstacles statistics, transmission and distribution lines Lightning Accidents account for a large proportion. Lightning to the power system has brought a lot of trouble and caused huge losses[1-3]. As the global climate continues to warm, the climate situation becomes even more complex, thunderstorms become more frequent, and the number and intensity of thunderstorms has also been improved, to the safe operation of the transmission line caused a lot of trouble, bring the power system a great loss[4]. Trip Transmission Line Lightning
Disturbance caused not only affect the normal power supply of the power system, increasing the maintenance workload of transmission lines and switching equipment and transmission lines due to lightning, thunder wave will invade substations along the road. And in the power system, the insulation of the strongest line, substation, followed by the weakest generator, if the device to protect power plants, substations imperfect, often causing damage to the insulation of their equipment, the impact of security of electricity supply[5]. Thus, well mine is one of the key transmission line power loss caused by lightning damage to the power system and reduce accidents. How to deal with lightning in the current volatile climate impact of transmission and effectively improve the security and stability of the transmission has a very important significance.

\section{MECHANISM AND CHARACTERISTICS OF LIGHTNING DISCHARGES}

Thundercloud is the accumulation of a large amount of charge of the clouds. Mechanism charged on thundercloud, generally considered, in the atmosphere saturated with steam, when met with strong updrafts, causes the charged droplets in the air, these charged droplets is driven by air, in a certain part of the clouds gradually together, form a charged thundercloud. The Thundercloud charges are generally not uniformly distributed in the cloud, but concentrated in a few live center. Measurements show that the upper part of the thundercloud positively charged, negatively charged lower portion. Positive charge distributed in a height of about $4-10 \mathrm{~km}$ clouds, the distribution of negative charge cloud height of approximately $1.5-5 \mathrm{~km}$. Thundercloud average electric field strength of $1.5 \mathrm{Kv} / \mathrm{cm}$, measured to the maximum before the thundercloud lightning electric field intensity $3.4 \mathrm{kv} / \mathrm{cm}$, and in the steady rain, only about $40 \mathrm{v} / \mathrm{cm}$. Direct hit to the ground from the edge of the discharge usually begins negative charge centers. Thundercloud discharge of earth typically includes several repetitive discharge process, and can be divided into each discharge pilot discharge, the main discharge, and afterglow discharge three main phases[6].

After Thundercloud with a charge, the charge concentrated in a few live centers, the number of charges between them are not exactly equal. When a point charge more, and in the vicinity of the electric field reaches its sufficient dielectric breakdown strength of air (about $25-30 \mathrm{kv} / \mathrm{cm}$ ), the air began to 
free, to make this part from the original state to a conductive insulated aisle. The formation of a conductive channel, called the pilot discharge. Pilot discharge is not continuous, the first pilot to land Thundercloud discharge is graded development leader at every level of development speed is very high, but each to a certain length (an average of about $25-50 \mathrm{~m}$ ) there is a $10-100$ us intervals. Therefore, its average speed is slow, the speed of light around about 1/1000. Pilot discharge discontinuity called classification guide, which lasted about $0.005-0.015$. The reason is generally interpreted as a classification guide: As in the pilot channel free is not very strong, it is not very good conductivity, Thundercloud down due to the charge will take some time, the charge to be the head of the channel increases, the electric field over the air free field strength, the pilot will also continue to develop.

In the early stages of the pilot channel is formed, its direction still some accidental factors, not fixed. But when it is a certain height from the ground, the induced charge appears on the surface of tall objects, so that the local field enhancement, development of the pilot channel will develop along its head between the induced charge concentration points. When the pilot passage between the head and the focus point with the oppositely charged distance is very small, about Thundercloud potential pilot channel end-to-ground (up IOMV), while the other end of the ground potential, so the rest of the air gap high electric field strength, so that the air gap rapidly released. Positive and negative charges generated free respectively upward, downward movement, the pilot passage and charge neutralization was hit, then began the second phase of the discharge, i.e., the main discharge phase. Main discharge phase of the time is very short, about 50-100us, moving speed of light speed of $1 / 20-1 / 2$; the main discharge current of up to thousands of security, up 200-300KA. When the clouds reach the main discharge, meaning the end of the main discharge phase. At this point, the thundercloud charge remaining, will continue along the main discharge channel down, this time called the afterglow discharge phase.

Power system caused by lightning over-voltage, overvoltage known as atmospheric. Thundercloud discharge on the device over-voltage, due to the impact arising from the thundercloud, is also known as the Lightning. Atmospheric over-voltage and over-voltage can be divided into direct lightning strike lightning overvoltage. Direct lightning strike to the transmission line conductors, the huge lightning current flows through the transmission line caused by over-voltage, over-voltage direct lightning strikes become; when lightning strikes or ground transmission line tower, due to electromagnetic induction and electrostatic induction on the transmission line conductors produced over-voltage, overvoltage lightning become[7].

Lightning occurs when the discharge time is very short, sometimes just will discharge about $0.01 \mathrm{~s}$, but it was in this very short time the release of tens of millions of voltage, have a very strong destructive moments. Lightning power systems have a huge impact and harm, and the main hazards are the following:1. high-voltage lightning effect will produce tens of thousands or even hundreds of thousands of high voltage in an instant, at the moment for electrical equipment caused great impact, it will be insulated equipment Jihuai moment, it is damaged, even serious when the explosion occurred. 2. Due to the effect of lightning transients, and its release pressure but also generated a strong current, these currents can even reach thousands of amps, thermal effect under the current moment a lot of heat, so that the relevant equipment metal and other facilities melt, causing an accident. 3. lightning current mechanical effect, in the event of being hit by lightning sometimes distorted objects will happen, tear or even explode. 4. lightning current that can hit things with lightning conductor induces a large number of properties opposite charge, when lightning too late diaspora, both will produce a high voltage discharge phenomenon resulting in a fire.

When lightning strikes the top of the tower, due to foot tower grounding resistance $\mathrm{R}$ is small, so there is reflection phenomenon. If $\mathrm{R}=0$, then in any case the tower will not appear on the ground. Then along with the current wave of voltage traveling wave invasion, had to change its polarity and then reflected back by the original channel, to offset the guarantee of zero potential state tower. But with this backwards reflected voltage traveling wave and a current traveling wave returns to the invasion a positive current, and returns a negative current, the result is equivalent to twice the current superimposed together. Therefore, it seems from the hit thing, disappeared voltage and current doubled. Of course, in fact, not really $\mathrm{R}$ is zero, so this conversion is not quite perfect; and then drop on $\mathrm{R}$, but also makes the line-to-ground lightning to get a potential, so that the voltage traveling wave on it appears and is accompanied by a wave of popular power. However, as usually only 1-20. Therefore this line of lightning electricity generated traveling waves is negligible. Therefore, we generally use the magnet on top of the tower or lightning rod lightning current measured, has been included in this theoretical reflection into account, so we generally measured lightning current I. That the most commonly used lightning current.

\section{LIGHTNING-SHIELDING DESIGN}

Transmission Line Lightning design mainly in the following aspects: a reasonable choice line path; erection of lightning conductor; neutral non-effectively grounded manner; lower tower grounding resistance; in some sections of the installation of surge arresters; erection coupling ground; a reasonable choice of insulation tie. From the above several mine design point of view, by nature can be divided into two categories, namely to avoid the lightning and thunder to improve the level of resistance of the device.

\section{A. reasonable choice line path}

Experience has shown that a large number of runs, the line being struck by lightning tends to focus on the line of certain areas. Called selective lightning area, otherwise known as easy strike zone. If we can avoid the easy route strike zone, or to strengthen the protection of the line easily strike zone, it is a fundamental measure to prevent mine victims. Practice shows that the following locations vulnerable to lightning strikes: a thunderstorm corridors, such as the mountain air and the wind in the valleys and canyons, etc.; surrounded by hills wet basin, as there are fish ponds, reservoirs, lakes and marshes around the tower, forest or bush, there are winding down the nearby hills, etc.; soil resistivity zone with mutations, such as 
geological fault zone rocks and soils, slopes and paddy junction, rocky river valley at the foot of the mountain there and so, the Leahy hit at low soil resistivity; the ground and the water table underground mine conductivity at higher; when the soil resistivity little difference, for example, good soil and vegetation in the hills Lei $\mathrm{Yi}$ hit on prominent hilltop, mountains to sunny and so on.

\section{B. erection lightning conductor;}

Erection of lightning conductor is the most basic and the most effective measures to protect the transmission line lightning. The main role of lightning conductor wire is to prevent lightning strikes, but also has the following effects: 1.diversion effect to reduce the lightning current flows through the tower, thus reducing the potential overhead; 2 . by coupling effect on the wire can be reduced voltage line insulator; 3 . the shielding effect of the wire can also reduce the over-voltage sensing wire.

Generally speaking, the line voltage is higher, the better use of the effect of lightning conductor, and lightning-line cost in line also lower the proportion (usually no more than $10 \%$ of the total cost of the line). Therefore, rules of order, $220 \mathrm{kV}$ and above voltage level transmission lines should be set up across the board lightning line, $110 \mathrm{kV}$ line in general should also be set up across the board lightning line. To play a protective role, lightning conductor should be grounded in a tower at each base. EHV transmission lines in the double lightning conductor, the normal operating current loop will be closed in each span consisting of two lines in lightning induced currents and cause power loss. To reduce this loss, and in order to serve as channels of communication lines and lightning protection can be lightning-line through a small gap on the ground (tower) insulation up. When lightning strikes, the gap breakdown, so lightning grounding wire.

\section{C. neutral non-effectively grounding}

In power system failures and accidents, at least more than $60 \%$ are single phase. However, the neutral point ungrounded power system single-phase ground fault occurs, remain balanced three-phase voltages and continue to supply the user, so that operators have sufficient time to find trouble spots and make timely treatment. $35 \mathrm{kV}$ and below the power system used in ungrounded or arc suppression coil grounded way. This will compensate for the short-circuit current flows through the point of failure, so that the arc can be self-extinguishing, self-healing system to normal operation, reducing recovery phase voltage failure on the rate of increase, decrease the likelihood of reignition make lightning strike caused a large Most singlephase ground fault can be automatically eliminated without causing phase short circuit and tripping. And in the two-phase or three-phase lightning, since the first one on the ground flashover phase corresponds to a lightning conductor, increasing diversion and not flashover phase of cooperation with evil, so that is not insulated from the flashover voltage drop, thereby increasing the level of resistance to lightning and power line circuit reliability. Therefore, the $35 \mathrm{kV}$ line of reinforced concrete poles and towers, we must do grounding. Considering the $35 \mathrm{kV}$ system is not directly grounded neutral point earthed power system, allowing the single-phase ground short run, then the circuit design, the line should be no part of the line as far as possible lightning conductors triangular arrangement, so that the top of a phase act as the role of lightning conductor lines. Erection of lightning into line segments, should be used horizontally aligned wire door type tower, due to the double lightning conductor for lightning current shunt, can reduce the potential of lightning mast, making lightning trip rate reduction; if there have been singlepole double pole alternatively, because the transition point and the lead single and double lightning line transition point from a triangular arrangement of the horizontal arrangement of the construction process is difficult to ensure that the same will result in the protection of the corner near the transition point lead is too large, and the opportunity to increase around the strike. Meanwhile, two lightning line also linked to each other in the top of the pole and ground deflectors were installed.

\section{D. reduce the tower grounding resistance;}

Ground Wire resistor matching foot tower when lightning can play a significant role in blood pressure, and therefore to $110 \mathrm{KV}$ concrete pole or tower above the line, is one of the most effective protective measures. Procedures required, there is lightning conductor line, the frequency of each base tower grounding resistance when dry lightning season should not exceed the values shown in Table 1 .

TABLE I. TOWER FREQUENCY GROUNDING RESISTANCE

\begin{tabular}{|l|c|c|c|c|c|}
\hline $\begin{array}{c}\text { Soil galvanic } \\
\text { rate }\end{array}$ & $\begin{array}{c}100 \text { and } \\
\text { below }\end{array}$ & $100-500$ & $\begin{array}{c}500- \\
1000\end{array}$ & $\begin{array}{c}1000- \\
2000\end{array}$ & $\begin{array}{c}\text { More } \\
\text { than } \\
2000\end{array}$ \\
\hline $\begin{array}{l}\text { Ground } \\
\text { Resistance }\end{array}$ & 10 & 15 & 20 & 25 & 30 \\
\hline
\end{tabular}

For $35-60 \mathrm{kV}$ concrete tower or pole lines, although generally add a lightning line of little significance, but still need to chase tower grounding. Because then if one phase is grounded due to lightning after flashover, it actually plays a role in lightning line, to a certain extent, can prevent further flashover other two phases. Grounding resistance is not restricted, but the average number of thunderstorm days over 40 years in areas not more than $30 \Omega$.

Cross-sectional area and the cross-sectional shape of the grounding of the grounding resistance value is not affected, therefore, the choice of material specifications grounding main consideration required corrosion and mechanical strength. Grounding materials commonly used steel. Artificial grounding, can be laid horizontally round, flat; can be laid perpendicular angle, pipe, bar and so on. Grounding device (including grounding and ground deflectors) conductor cross-section must comply with the thermal stability and grading requirements. Laid in place corrosive grounding device should be taken hot tin, galvanized anti-corrosion measures in accordance with the nature of corrosion, or appropriate to increase the cross-section. $\mathrm{RC}$ rod iron cross arms and reinforced concrete cross lightning line Tam line stand, wire cross arm and the fixed part or porcelain insulator between the fixed portion of the cross arm, should have a reliable electrical connection and connected to ground deflectors. Non-prestressed reinforcement as the main lever up and down has been connected with banding or welded 
into electrical path, non-prestressed reinforcement can double as ground deflectors. In small ground fault current system, if no reliable measures should not serve as a ground prestressing steel deflectors. Doubles as a fixed part of the use of reinforced steel ground deflectors and ground nuts, iron cross arm or porcelain cross arm should have a reliable electrical connection. Topical ground deflectors can be galvanized steel, the section should not be less than $25 \mathrm{~mm}$ '.

\section{E. arrester installed in some sections}

Erection of lightning across the board so that the line, we can not completely rule out the possibility of over-voltage on the wire, and install the line due to lightning arrester allows overvoltage generated when the amplitude exceeds a certain action, the lightning current to provide a low impedance path in to vent into the earth, thus limiting the voltage increases, the protection of the line, safety equipment. When lightning strikes the tower, part of the lightning current flows through the lightning conductor adjacent tower, another part of the lightning into the earth passing through the tower, tower grounding resistance was transient resistance characteristics, generally used to characterize the impact of grounding resistance. After the installation of surge arresters, when the transmission line being struck by lightning, lightning current diversion will change, part of the lightning current from the lightning incoming line adjacent tower, part of the body into the ground through the tower, when the lightning current exceeds a certain value, adding arrester action shunt. Most of the lightning current flows from the arrester wire, spread to the adjacent tower. Lightning current flows through the wire and wire lightning, electromagnetic induction between the wires, the wires and lightning in the line components were combined to produce a curse. Because lightning is far greater than the shunt shunt lines from lightning lightning current, this diversion of cooperation with evil will make wire potential to improve, the potential difference between the wires and the overhead is less than the flashover voltage insulator strings, insulator does not flashover occurs, therefore, has a good line arrester clamp potential, which is the line lightning arrester distinctive features.

\section{F. erection ground coupling}

When there are difficulties in reducing the tower grounding resistance, can be used to set up measures to curse the ground together, ie below the wire (or near) the re-erection of a ground. It has strengthened the role of the major disaster together with the wire between the lightning conductor, thereby reducing the voltage across the insulator strings counterattack voltage and induced voltage components; adds overhead to the adjacent tower lightning lightning current shunt. Operating experience shows that disaster co-ground lightning trip rate in reducing the effect is significant, especially in the mountainous areas of the transmission line effect is more obvious. $110 \mathrm{kV}$ and $220 \mathrm{kV}$ have had our lightning using wire line had trouble co-ground installation practices.

\section{G. reasonable choice of transmission line insulation coordination.}

Insulation coordination and comprehensive consideration of the electrical equipment in the power system can withstand a variety of voltage (working voltage and over-voltage), the protection of property and equipment insulation device to withstand voltage characteristics of the various roles, reasonably determine the equipment necessary insulation level accident damage so the equipment cost, maintenance costs and equipment failure caused the insulation to achieve the highest goal total in the economic and security benefits of running.

Insulation with the ultimate goal is to determine the level of insulation of electrical equipment, available $1 \mathrm{~min}$ power frequency voltage withstand test to test for electrical equipment, this value represents the insulation of lightning, operating over the total voltage tolerance levels, as long as the device can work frequency voltage withstand test, it is considered that the device is experiencing the atmosphere in operation, the internal over-voltage, can ensure safety. Overhead transmission line insulation with the design is to solve the tower and may discharge pathway from the central archives of various (including wire on the tower, lightning conductors on the line, wire-to-ground, between different phase conductors) insulation options and cooperating issue.

\section{CONCLUSION}

As can be seen from the above design principles to enhance the design of overhead transmission line lightning, lightning trip can greatly reduce the rate of overhead lines, avoid lightning accident losses expansion, providing more reliable protection for the safe operation of the power system.

\section{REFERENCES}

[1] R. E. Koch, "Design of Zinc Oxide Transmission Line Arrestes for APPlieation on $138 \mathrm{kV}$ Towers," IEEETrans.onPAS, vol. 104, pp. 2426,1985 .

[2] L. Dellera, E.Garbagnati, "Lightning stroke simulation by means of the leader Propagation model parts I and II," IEEE Trans. on Power Delivery, vol. 5, pp. 2009-2029, 1990.

[3] S. y. Zhu, , Y. r. Deng, " Research on shielding lightning performance of electric transmission line with the improved EGM," High Voltage Apparatus, vol. 44, pp. 56-58, 2008.

[4] F. Young, J. M. Clayton, A. R. Hileman, "Shielding of Transmission Lines," IEEE Transactions on Power Apparatus and Systems, vol. 82, pp. 132-154, 1963.

[5] G. Qian, X. Wang, X. Xu, "Profile along the transmission line from the direction of change in the probability of shielding failure," High Voltage Technology, vol. 25, pp. 23-25, 1999.

[6] A. J. Eriksson, "The Incidence of Lightning Strikes to Power Line," IEEE Tran. On Power Delivery, vol. 2, pp. 861-870, 1987.

[7] X. Kai, "Overhead lines against lightning strike around Practical Technology," High Voltage Technology, vol. 6, pp. 1301-1302, 2008. 